\title{
Kajian Area Penyinaran Dan Nilai Intensitas Pada Peralatan Blue Light Therapy
}

\author{
Dewa Ayu Sri Santiari ${ }^{1}$, Putu Agus Mahadi Putra ${ }^{2}$
}

\begin{abstract}
The case of a yellow baby (hyperbilirubinemia) is one of the most common conditions in newborns. One of the measures to reduce bilirubin levels in a baby is by phototherapy using blue light therapy. There are two types of blue light therapy equipment that is currently used in Cempaka area of Sanglah hospital, namely: blue light therapy fluorescent lamps and blue light therapy LED lights. Both types of equipment have different shapes and light sources. The result of light source form analysis on both therapy equipment shows that blue light therapy of rectangular fluorescent lamp will produce a wider irradiation area than blue light therapy LED which only produce limited exposure area on work surface. As for the intensity of the rays obtained that at the same distance, which is $30 \mathrm{~cm}$ then the blue light therapy fluorescent will produce an average value of higher intensity of $12 \mu \mathrm{W} / \mathrm{cm}^{2} / \mathrm{nm}$ compared with blue light therapy LED which only yields the average value $6 \mu \mathrm{W} / \mathrm{cm} 2 / \mathrm{nm}$. Based on wider irradiation areas and higher intensity values indicate that blue light therapy fluorescent lights are more effective as phototherapy devices compared with blue light therapy LED.
\end{abstract}

Keywords- —Blue light therapy, Irradiation area, Irradiance intensity

Intisari- Kasus bayi kuning (hiperbilirubinemia) merupakan salah satu keadaan yang sering ditemukan pada bayi baru lahir. Salah satu tindakan untuk menurunkan tingkat bilirubin pada bayi kuning adalah dengan fototerapi menggunakan blue light therapy. Ada dua jenis peralatan blue light therapy yang saat ini dipergunakan pada ruang Cempaka di rumah sakit Sanglah, yaitu : blue light therapy lampu fluorescent dan blue light therapy lampu LED. Kedua jenis peralatan tersebut memiliki bentuk dan sumber cahaya yang berbeda. Hasil analisa bentuk sumber cahaya pada kedua peralatan therapy menunjukkan bahwa blue light therapy lampu fluorescent yang berbentuk persegi panjang akan menghasilkan area penyinaran yang lebih luas dari blue light therapy $L E D$ yang hanya menghasilkan area penyinaran terbatas pada permukaan bidang kerja. Sedangkan untuk intensitas sinarnya diperoleh bahwa pada jarak yang sama, yaitu $30 \mathrm{~cm}$ maka blue light therapy lampu fluorescent akan menghasilkan nilai rata-rata intensitas yang lebih tinggi sebesar $12 \mu \mathrm{W} / \mathrm{cm}^{2} / \mathrm{nm}$ dibandingkan dengan blue light therapy $L E D$ yang hanya menghasilkan nilai rata-rata intensitas sebesar $6 \mu \mathrm{W} / \mathrm{cm}^{2} / \mathrm{nm}$. Berdasarkan area penyinaran yang lebih luas dan nilai intensitas yang lebih tinggi menunjukkan bahwa blue light therapy lampu flourescent lebih efektif sebagai alat fototerapi dibandingkan dengan blue light therapy lampu $L E D$

Kata Kunci- - Blue light therapy, Area penyinaran, Intensitas penyinaran

Dosen Teknologi Rekayasa Elektromedik, Institut Ilmu Kesehatan Medika Persada Bali, Denpasar, Bali, INDONESIA; e-mail:1'dwayusanti@gmail.com, ${ }^{2}$ mahadi.putra@gmail.com.

\section{PENDAHULUAN}

Kasus bayi kuning (hiperbilirubinemia) merupakan salah satu keadaan yang sering ditemukan pada bayi baru lahir. Sekitar 50-70\% kelahiran bayi cukup bulan dan $80-90 \%$ bayi prematur mengalami hiperbilirubinemia[1]. Jaundice atau hiperbilirubinemia terjadi karena kadar bilirubin yang terlalu tinggi dalam darah. Keadaan ini terjadi karena belum sempurnanya fungsi organ hati (liver) pada bayi baru lahir untuk memecah dan mengeluarkan bilirubin dari tubuh. Ketika hal ini terjadi, maka kulit dan bagian putih pada mata bayi berwarna kuning (ikterus). Berdasarkan kadar bilirubinnya maka ikterus pada tubuh bayi terbagi menjadi lima bagian dengan daerah yang terbesar terletak pada telapak tangan dan kaki [2].

Kadar bilirubin tidak terkonjugasi pada kelahiran cukup bulan dapat mencapai $6-8 \mathrm{mg} / \mathrm{dL}$ pada usia 3 hari, setelah itu berangsur turun. Sedangkan pada bayi prematur, hiperbilirubinemia terjadi lebih dini dengan kadar bilirubin yang naik perlahan tetapi dengan kadar puncak lebih tinggi, yaitu mencapai $10-12 \mathrm{mg} / \mathrm{dL}$ pada hari ke-5 dan dapat naik menjadi $>15 \mathrm{mg} / \mathrm{dL}$ [1]. Bila kuning terlihat pada bagian tubuh manapun pada hari pertama dan terlihat pada lengan, tungkai, tangan dan kaki pada hari kedua, maka digolongkan sebagai ikterus sangat berat dan memerlukan terapi sinar secepatnya [3].

Tindakan memberikan terapi sinar (phototherapy) merupakan salah satu cara untuk menurunkan kadar bilirubin dalam darah [4]. Pada awalnya terapi sinar dilakukan dengan mempergunakan cara alami, yaitu dengan sumber dari sinar matahari. Tetapi karena terbatasnya waktu yang efektif untuk penyinaran, yaitu hanya dapat dilakukan antara rentang waktu pukul 07.00-09.00 pagi maka terapi ini tidak dapat dilakukan sepanjang hari [5]. Untuk mengatasi hal tersebut maka dipergunakan alat terapi yang bersumber dari cahaya buatan, yang sering disebut dengan blue light therapy. Alat terapi ini mempergunakan lampu yang memancarkan spektrum cahaya biru dengan panjang gelombang berkisar antara 450-490nm [10]. Adapun jarak penyinaran antara bayi dengan sumber sinar (lampu) saat dilakukan terapi adalah $\pm 30-50 \mathrm{~cm} \mathrm{[5]}$.

Umumnya lampu fluorescent bentuk tabung memanjang merupakan jenis lampu yang dipergunakan untuk blue light therapy di puskesmas, klinik bersalin dan rumah sakit. Selain menggunakan lampu fluorescent $(T L)$ maka saat ini peralatan blue light therapy ada pula yang menggunakan lampu LED (light emitting diode) sebagai sumber penyinarannya. Lampu LED merupakan lampu jenis semikonduktor yang dapat memancarkan cahaya monokromatik. Ditemukannya diode yang mampu memancarkan cahaya warna biru merupakan langkah awal penggunaan lampu ini pada bidang kesehatan khususnya fototerapi.

Dewa Ayu Sri Santiari : Kajian Area Penyinaran Dan Nilai Intensitas... $\quad$ p-ISSN:1693 - 2951; e-ISSN: $2503-2372$

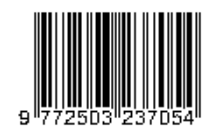


Peralatan blue light therapy yang saat ini dipergunakan pada ruang Cempaka di rumah sakit Sanglah ada dua jenis, yaitu blue light therapy dengan lampu fluorescent tabung panjang dan blue light therapy dengan lampu LED. Blue light therapy dengan tube lamp $20 \mathrm{~W}$ memiliki bentuk persegi panjang. Sedangkan blue light therapy dengan lampu LED memiliki bentuk yang lebih kecil dengan dua sisi yang berbeda. Satu sisi permukaan berbentuk persegi panjang sedangkan sisi yang lain berbentuk melengkung, tempat terpasangnya 5 buah lampu super LED. Kedua peralatan blue light therapy ini memiliki spesifikasi panjang gelombang yang memenuhi rentang spektral cahaya yang ditentukan untuk fototerapi, yaitu berkisar 450-490nm [10][13]. Akan tetapi karena kedua jenis peralatan ini memiliki bentuk dan sumber cahaya yang berbeda maka perlu dilakukan penelitian terhadap luas area penyinaran dan nilai intensitas yang dihasilkan. Ini terkait dengan efektifitas fototerapi yang selain dipengaruhi oleh panjang gelombang sinar lampu, juga tergantung pada intensitas cahaya (irradiance), jarak antara lampu dengan bayi, dan luas area tubuh bayi yang terpapar sinar lampu [10][12]. Semakin tinggi intensitas sinar dan semakin dekat jarak fototerapi dengan tubuh bayi maka semakin cepat penurunan kadar bilirubin [7][11]. Luasnya permukaan tubuh neonatus (bayi) yang terpapar sinar membawa dampak pengobatan lebih baik dibandingkan dari banyaknya jumlah lampu yang digunakan [11].

Untuk mengetahui luas area dan besar intensitas penyinaran yang dihasilkan oleh kedua blue light therapy maka dilakukan penelitian pada kedua peralatan tersebut dengan jarak sumber cahaya yang diatur antara $30-50 \mathrm{~cm}$. Sehingga dari penelitian ini dapat diketahui peralatan blue light therapy yang efektif dipergunakan sebagai alat fototerapi dari sisi area penyinaran yang lebih luas dengan nilai intensitas yang lebih tinggi.

\section{TINJAUAN PUSTAKA}

A. Cahaya

Cahaya matahari dan cahaya lampu adalah dua jenis cahaya yang ada dalam kehidupan kita sehari-hari. Jika bumi tidak mendapat cahaya dari matahari, maka bumi akan gelap gulita dan dingin sehingga tidak mungkin ada kehidupan. Sumber cahaya yang merupakan bagian dari kelompok gelombang elektromagnetik, memancarkan energi dalam bentuk gelombang. Spektrum gelombang elektromagnetik mencakup rentang frekuensi yang lebar serta tidak memerlukan medium untuk merambat. Dalam ruang hampa, gelombang cahaya dapat merambat dengan kecepatan yang sangat cepat, yaitu $3 \times 10^{8} \mathrm{~m} / \mathrm{s}$, artinya dalam waktu satu sekon cahaya dapat menempuh jarak $300.000 .000 \mathrm{~m}$ atau $300.000 \mathrm{~km}$ [14].

Panjang gelombang cahaya tampak berukuran antara 380 $\mathrm{nm}$ sampai dengan $760 \mathrm{~nm}$. Dimana cahaya yang tampak berwarna biru memiliki panjang gelombang 450-490nm. Cahaya dengan panjang gelombang inilah yang diperlukan untuk blue light therapy pada hiperbilirubin [6].

\section{B. Lumen}

Flux cahaya $(\phi)$ adalah jumlah keseluruhan watt cahaya dengan satuan lumen, disingkat dengan $\mathrm{lm}$. Satu watt cahaya kira - kira sama dengan 680 lumen. Angka perbandingan 680 ini dinamakan ekivalen pancaran fotometris. Intensitas cahaya (I) adalah flux cahaya persatuan sudut ruang yang dipancarkan ke suatu arah tertentu yang diukur dalam satuan candela (cd) [15].

\section{Intensitas Penyinaran}

Intensitas penyinaran atau iluminasi atau kuat penyinaran adalah flux cahaya yang jatuh pada suatu bidang atau permukaan, sehingga satuan intensitas penyinaran adalah lumen / $\mathrm{m} 2$ atau Lux (Lx) dengan lambang E. Sehingga dapat dikatakan bahwa $1 \mathrm{Lux}=1$ lumen/m2. Intensitas penyinaran di suatu bidang karena suatu sumber cahaya dengan intensitas I, berkurang dengan kuadrat dari jarak antara sumber cahaya dan bidang itu [15]. Nilai intensitas penyinaran pada suatu titik pada bidang kerja dapat dihitung dengan mengacu pada "(1)" sebagai berikut :

$$
\mathrm{E}_{\mathrm{P}}=\frac{\mathrm{I}}{\mathrm{r}^{2}} \operatorname{lux}
$$

Dimana :

Ep : intensitas penyinaran di suatu titik $\mathrm{P}$ dari bidang yang diterangi, dinyatakan dalam satuan lux.

I : intensitas sumber cahaya dalam satuan candela.

$\mathrm{r}$ : jarak dari sumber cahaya ke titik $\mathrm{P}$, dinyatakan dalam meter.

Nilai rata-rata intensitas penyinaran diperoleh dengan mengacu pada “(2)" sebagai berikut [21]:

$$
\bar{x}=\frac{\sum_{i=1}^{n} x_{i}}{n}
$$

Dimana :

$\bar{X}$ : nilai rata-rata intensitas hasil konversi

$\mathrm{n}$ : banyaknya data

$X_{i}$ : nilai data intensitas ke-i hasil konversi

\section{Lampu Fluorescent}

Lampu fluorescent sering pula disebut dengan lampu tube luminescent atau tube lamp (TL), yaitu lampu yang berbentuk "tube" atau tabung. Teknologi fluorescent $(T L)$ adalah lampu yang berbentuk tabung hampa dengan kawat pijar dikedua ujungnya (elektroda), tabung tersebut diisi dengan merkuri dan gas argon yang bertekanan rendah. Tabung lampunya yang terbuat dari gelas juga dilapisi (coating) oleh lapisan fosfor. Saat dialiri arus listrik, elektroda akan memanas dan menyebabkan elektron-elektron berpindah tempat dari satu ujung ke ujung lainnya. Energi listrik tersebut juga akan mengakibatkan merkuri yang sebelumnya adalah cairan berubah menjadi gas. Perpindahan elektron akan bertabrakan dengan atom merkuri sehingga energi elektron akan meningkat ke level yang lebih tinggi. Elektron-elektron akan melepaskan cahaya saat energi elektron-elektron tersebut kembali ke level normalnya [16][17].

\section{E. Lampu LED (Light Emitting Diode)}

LED (Light Emitting Diode) adalah bahan semikonduktor yang mengeluarkan cahaya ketika arus listrik melaluinya [17]. Sebagaimana dioda lainnya, $L E D$ terdiri dari pasangan bahan semikonduktor $\mathrm{P}$ dan N. Bila sumber arus searah diberikan kepada $L E D$ maka arus mengalir dari sisi-P (Anoda) ke sisi-N 
Majalah Ilmiah Teknologi Elektro, Vol. 17, No. 3, September - Desember 2018

DOI: https://doi.org/10.24843/MITE.2018.v17i01.P0X

(Katoda) tetapi tidak dalam arah sebaliknya. Pembawa muatan mengalir ke junction dari elektroda. Pada saat elektron bertemu lubang (hole) maka akan terjadi pelepasan energi dalam bentuk foton (cahaya). Efek ini dikenal dengan electroluminescence. [16][17]. Cahaya yang dihasilkan LED bermacam-macam tergantung pada komposisi dan kondisi material semikonduktor yang digunakan [16].

\section{F. Fototerapi (Terapi Sinar)}

Fototerapi merupakan terapi menggunakan sinar yang dapat dilihat secara kasat mata untuk pengobatan hiperbilirubinemia [7]. Tujuan terapi ini adalah membatasi peningkatan serum bilirubin dan mencegah penumpukan di dalam otak yang dapat menyebabkan komplikasi neurologis permanen yang serius [9]. Keberhasilan pelaksanaan perawatan bayi yang mengalami hiperbilirubinemia sangat tergantung dari efektifitas fototerapi dan minimnya komplikasi yang terjadi [7]. Panjang gelombang sinar yang paling efektif untuk menurunkan kadar bilirubin adalah sinar biru dengan panjang gelombang 450-490nm. Sinar biru lebih baik dalam menurunkan kadar bilirubin dibandingkan dengan sinar biru-hijau, sinar putih, dan sinar hijau [8].

Intensitas sinar yang diberikan menentukan efektifitas dari fototerapi. Alat ukur radiometer atau luxmeter adalah alat ukur yang dipergunakan untuk mengukur intensitas sinar. Penelitian di San Francisco menunjukkan bahwa fototerapi standar dengan intensitas sinar $8-10 \mu \mathrm{W} / \mathrm{cm}^{2} / \mathrm{nm}$ dan fototerapi intensif dengan intensitas sinar $\geq 30 \mu \mathrm{W} / \mathrm{cm}^{2} / \mathrm{nm}$ cukup signifikan dalam menurunkan kadar bilirubin [9]. Ini juga sesuai dengan definisi terapi intensif dari American Academy of Pediatrics (APP) yang menyatakan bahwa fototerapi intensif adalah fototerapi yang menggunakan intensitas sinar sedikitnya $30-40 \mu \mathrm{W} / \mathrm{cm}^{2} / \mathrm{nm}$, dengan penyinaran yang dapat mencakup seluruh permukaan tubuh neonatus (bayi)[11].

\section{G. Alat Blue Light Therapy}

Fungsi terapi sinar biru adalah mengubah bilirubin menjadi senyawa yang larut dalam air sehingga dapat dikeluarkan dari tubuh bayi [5]. Alat ini terdiri dari sumber cahaya yang memancarkan cahaya biru dengan panjang gelombang $450-490 \mathrm{~nm}$.

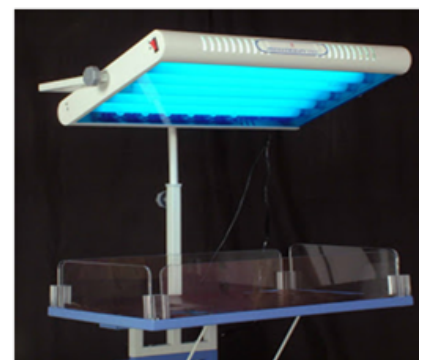

Gambar 1. Blue light therapy dengan Lampu Fluorescent (TL)

Alat blue light therapy pada gambar 1 menggunakan lampu fluorescent bentuk tabung dengan panjang $60 \mathrm{~cm}$. Jumlah lampu untuk 1 unit alat ini, dapat terdiri dari 1-5 buah lampu fluorescent khusus dengan daya 20W. Lampu fluorescent khusus ini dapat memancarkan sinar biru [19].

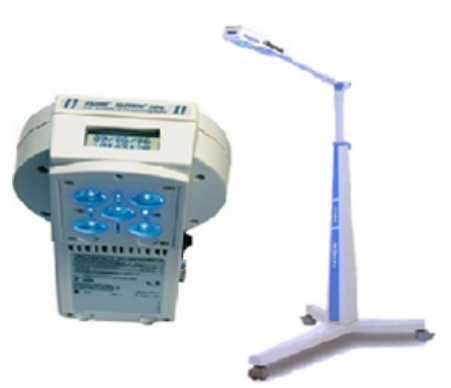

Gambar 2. Blue light therapy dengan lampu LED

Alat blue light therapy pada gambar 2 menggunakan lampu LED warna biru. Alat ini untuk 1 unitnya, terdiri dari 5 buah lampu super LED [18].

\section{H. Lux Meter}

Lux meter adalah alat yang digunakan untuk mengukur besarnya intensitas penyinaran di suatu tempat. Untuk mengetahui besarnya intensitas penyinaran maka diperlukan sebuah sensor yang cukup peka dan linier terhadap cahaya. Semakin jauh jarak antara sumber cahaya ke sensor maka akan semakin kecil nilai yang ditunjukkan lux meter. Ini membuktikan bahwa semakin jauh jaraknya maka intensitas penyinarannya akan semakin berkurang. Alat ini memperlihatkan hasil pengukuran menggunakan format digital yang terdiri dari sebuah sensor dan rangka. Sensor tersebut diletakan pada sumber cahaya yang akan diukur intensitasnya [20].

Sensor yang digunakan pada alat ini adalah photo diode. Sensor ini termasuk ke dalam jenis sensor cahaya atau optic. Sensor cahaya atau optic adalah sensor yang mendeteksi perubahan cahaya dari sumber cahaya, pantulan cahaya ataupun bias cahaya yang mengenai suatu daerah tertentu. Kemudian hasil dari pengukuran yang dilakukan akan ditampilkan pada layar panel [20].

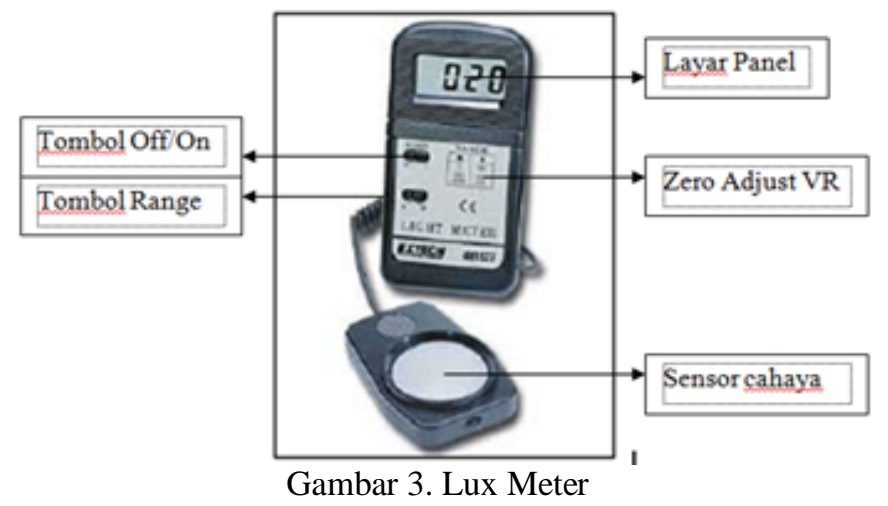

Berbagai jenis cahaya yang masuk pada luxmeter baik itu cahaya alami ataupun buatan akan mendapatkan respon yang berbeda dari sensor. Berbagai warna yang diukur akan menghasilkan suhu warna yang berbeda, dan panjang gelombang yang berbeda pula. Oleh karena itu hasil yang ditampilkan oleh layar panel adalah kombinasi dari efek panjang gelombang yang ditangkap oleh sensor photo diode.

\section{METHODOLOGI}


Peralatan blue light therapy yang diteliti pada paper ini adalah peralatan terapi yang dipergunakan di ruang Cempaka Rumah Sakit Sanglah Denpasar. Penelitian ini merupakan penelitian eksperimen, yang dilakukan untuk mengetahui pancaran intensitas dan area penyinaran yang dihasilkan oleh peralatan blue light therapy baik yang menggunakan lampu $T L$ maupun yang menggunakan lampu LED. Pengukuran intensitas penyinaran dilakukan pada bidang kerja berupa tempat tidur bayi di 15 titik yang berbeda. Adapun jarak ketinggian antara lampu dengan permukaan tempat tidur bayi di atur antara $30-50 \mathrm{~cm}$ dengan selisih jarak sebesar $5 \mathrm{~cm}$. Alat ukur luxmeter adalah alat yang dipergunakan untuk mengukur besar intensitas penyinaran yang dihasilkan oleh alat blue light therapy. Adapun variabel-variabel yang terkait pada paper ini adalah sebagai berikut :

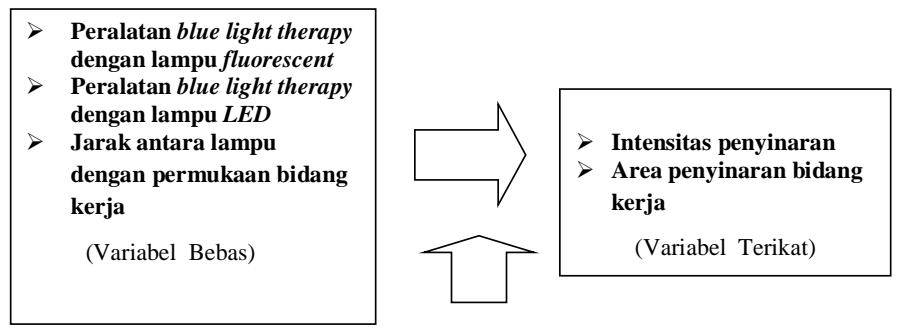

\section{Gambar 4. Bagan Konsep}

Data untuk analisa paper ini adalah data primer yang bersumber dari hasil pengukuran pada alat yang diteliti. Data primer diperoleh dari hasil pengukuran intensitas penyinaran pada titik-titik pengukuran yang ditentukan. Adapun jarak ketinggian antara lampu dengan permukaan tempat tidur bayi di atur antara $30-50 \mathrm{~cm}$. Data primer hasil pengukuran intensitas penyinaran dan area bidang kerja yang disinari dari masing-masing peralatan blue light therapy inilah yang kemudian akan dibandingkan dan dianalisa. Titik-titik yang diukur pada paper ini dapat dilihat pada gambar 5 .

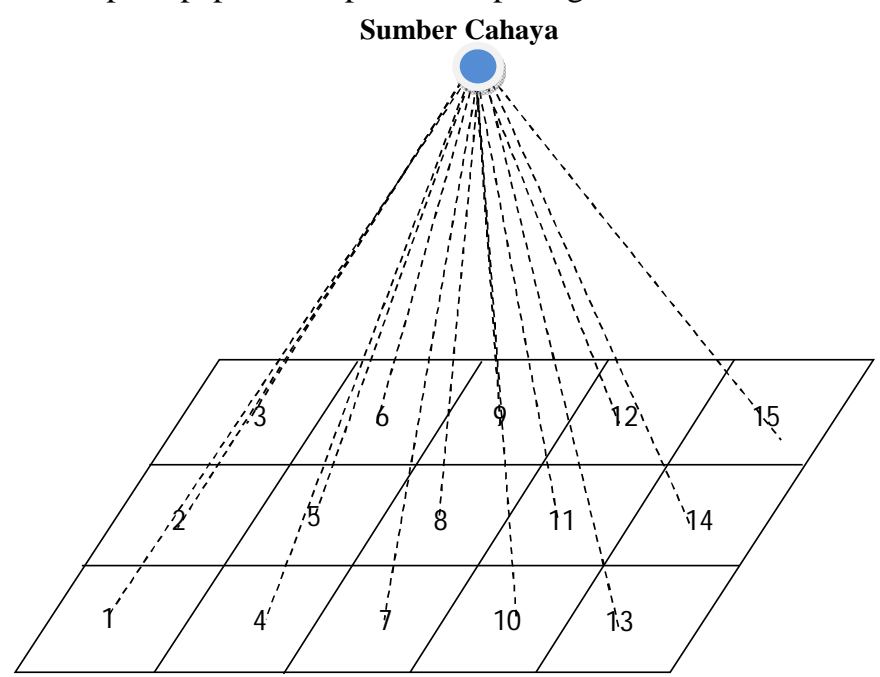

Gambar 5. Titik-titik Pengukuran Intensitas Penyinaran
A. Pengukuran Dimensi Blue Light Therapy Lampu Fluorescent

Pengukuran dimensi pada gambar 6 menunjukkan hasil bahwa blue light therapy lampu fluorescent memiliki panjang $65 \mathrm{~cm}$, lebar $35 \mathrm{~cm}$ dengan ketinggian $6,5 \mathrm{~cm}$.

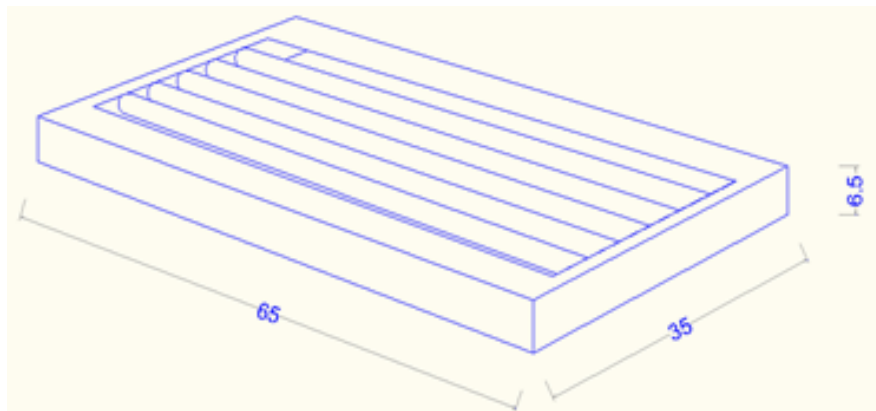

Gambar 6. Dimensi Blue light therapy Lampu Fluorescent

B. Pengukuran Dimensi Blue Light Therapy Lampu LED

Pengukuran dimensi pada gambar 7 menunjukkan hasil bahwa blue light therapy lampu LED memiliki panjang $23.5 \mathrm{~cm}$, lebar $10 \mathrm{~cm}$, dengan ketinggian $6 \mathrm{~cm}$. Sedangkan untuk penempatan lampu $L E D$ berbentuk persegi empat dengan ukuran $10 \times 10 \mathrm{~cm}$.

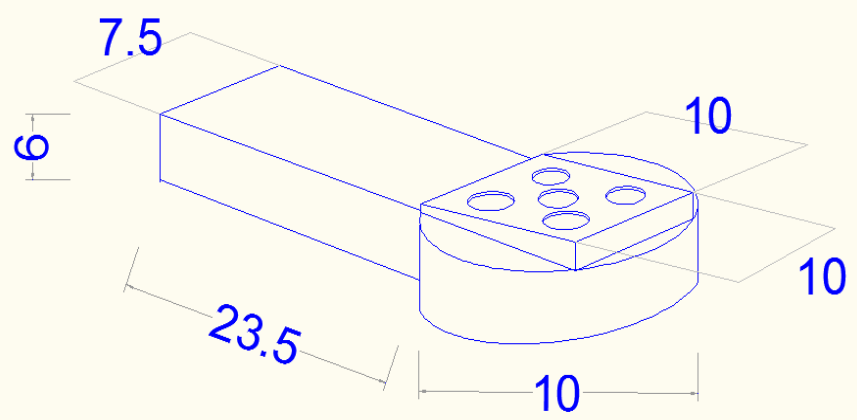

Gambar 7. Dimensi Blue Light Therapy Lampu Fluorescent

\section{Pengukuran Intensitas Penyinaran}

Pengukuran intensitas penyinaran pada penelitian ini dilakukan pada permukaan tempat tidur bayi (bidang kerja) di 15 titik yang berbeda dengan menggunakan alat ukur luxmeter. Pengukuran dimulai sesuai dengan penomoran pada bidang kerja. Untuk jarak antara sumber cahaya (lampu) dengan bidang permukaan yang disinari, ditentukan mulai $30 \mathrm{~cm}$, $35 \mathrm{~cm}, 40 \mathrm{~cm}, 45 \mathrm{~cm}$ sampai dengan $50 \mathrm{~cm}$.

Penempatan posisi lampu blue light therapy pada penelitian ini adalah sejajar dengan bidang kerja permukaan yang diukur (sudut kemiringan lampu adalah $0^{\circ}$ ) seperti terlihat pada gambar 8 .

\section{SIMULASI DAN PEMBAHASAN}




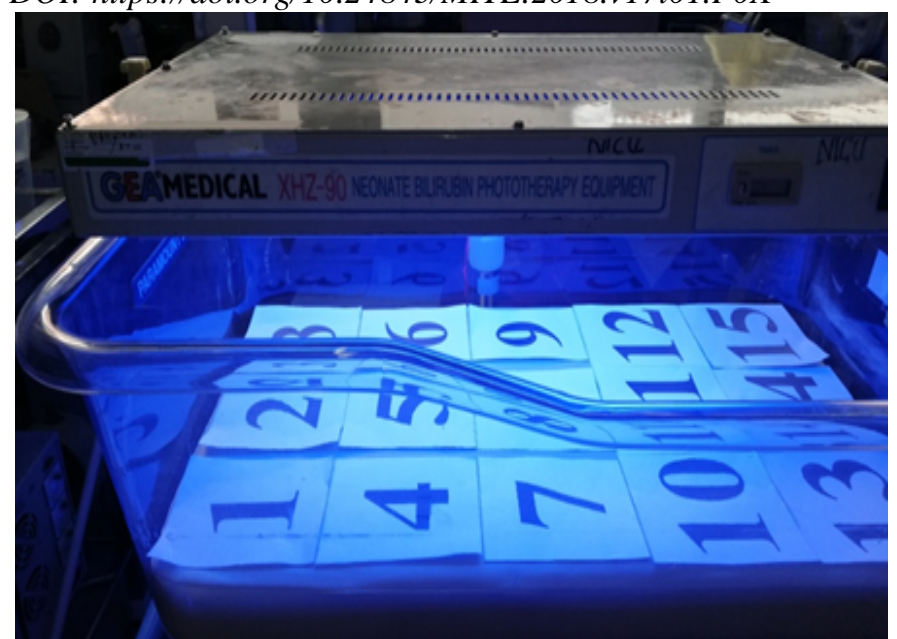

Gambar 8. Penempatan Posisi Lampu Blue Light Therapy

Besar intensitas sinar pada beberapa hasil penelitian sebelumnya menunjukkan bahwa intensitas sinar ditentukan dalam satuan $\mu \mathrm{W} / \mathrm{cm}^{2} / \mathrm{nm}$. Sehingga hasil pengukuran intensitas penyinaran blue light therapy dengan satuan lux akan dikonversikan ke dalam satuan $\mu \mathrm{W} / \mathrm{cm}^{2} / \mathrm{nm}$. Proses konversi dilakukan dengan menggunakan aplikasi dari www.endmemo.com. Hasil konversi dari aplikasi yang berbentuk bilangan desimal dengan satuan $\mathrm{W} / \mathrm{cm}^{2} / \mathrm{nm}$, kemudian dirubah ke dalam satuan $\mu \mathrm{W} / \mathrm{cm}^{2} / \mathrm{nm}$. Dimana hasil akhirnya kemudian dibulatkan.

D. Pengukuran Intensitas Penyinaran Blue Light Therapy Lampu Flourescent Pada Jarak $30 \mathrm{~s} / \mathrm{d} 50 \mathrm{~cm}$

Gambar 9 menunjukkan hasil penyinaran blue light therapy lampu fluorescent pada jarak $30 \mathrm{~cm}$.

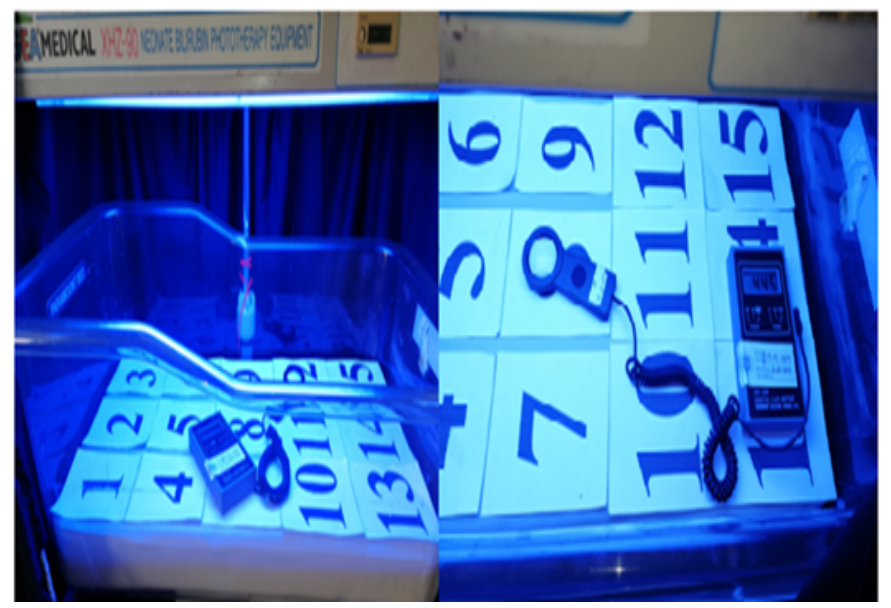

Gambar 9. Penyinaran BLT Lampu Flourescent pada Jarak $30 \mathrm{~cm}$

Hasil konversi pengukuran intensitas penyinaran blue light therapy lampu flourescent (TL) pada jarak $30 \mathrm{~cm}$ dalam $\mu \mathrm{W} / \mathrm{cm}^{2} / \mathrm{nm}$ dapat dilihat pada tabel I. Angka 1 sampai dengan 15 pada pojok kiri atas menunjukkan titik-titik pengukuran pada bidang kerja. Sedangkan nilai pada pojok kanan bawah adalah nilai konversi pengukuran intensitas penyinaran $B L T$.
Tabel I.

HASIL KONVERSI PENGUKURAN INTENSITAS PENYINARAN BLT TL JARAK $30 \mathrm{CM}$

\begin{tabular}{|rr|lr|lr|}
\hline 1 & $\mathbf{8}$ & & $\mathbf{1 2}$ & & $\mathbf{1 1}$ \\
\hline 4 & $\mathbf{1 2}$ & & $\mathbf{1 5}$ & & $\mathbf{1 5}$ \\
\hline 7 & $\mathbf{1 3}$ & & $\mathbf{1 6}$ & & $\mathbf{1 5}$ \\
\hline 10 & & 11 & & 12 & \\
& $\mathbf{1 2}$ & & $\mathbf{1 4}$ & & $\mathbf{1 3}$ \\
\hline 13 & & 14 & & 15 & \\
& $\mathbf{8}$ & & $\mathbf{9}$ & & $\mathbf{9}$ \\
\hline
\end{tabular}

Dengan mengacu pada (2) maka diperoleh nilai rata-rata intensitas penyinaran sebesar $12 \mu \mathrm{W} / \mathrm{cm}^{2} / \mathrm{nm}$. Kemudian berdasarkan tabel I maka dihasilkan grafik kontur intensitas penyinaran seperti ditunjukkan pada gambar 10 .

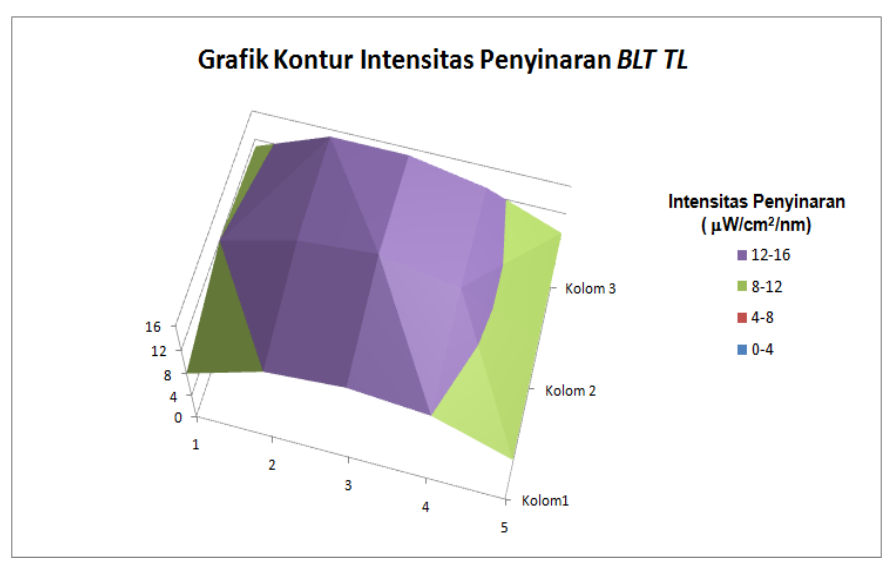

Gambar 10. Grafik Kontur Intensitas Penyinaran BLT TL pada Jarak $30 \mathrm{~cm}$

Tabel I menunjukkan hasil konversi pengukuran intensitas penyinaran blue light therapy lampu flourescent pada jarak 30 $\mathrm{cm}$. Pada tabel tersebut terlihat bahwa range nilai intensitas penyinaran pada semua titik pengukuran berada pada nilai 8 $16 \mu \mathrm{W} / \mathrm{cm}^{2} / \mathrm{nm}$, dengan nilai intensitas tertinggi berada pada titik ke-8 sebesar $16 \mu \mathrm{W} / \mathrm{cm}^{2} / \mathrm{nm}$. Adapun nilai rata-rata intensitas penyinaran pada saat blue light therapy lampu flourescent terpasang $30 \mathrm{~cm}$ dari bidang kerja adalah sebesar $12 \mu \mathrm{W} / \mathrm{cm}^{2} / \mathrm{nm}$.

Data pada tabel I menghasilkan grafik kontur intensitas penyinaran blue light therapy lampu fluorescent (gambar 10). Pada grafik tersebut terlihat bahwa seluruh area permukaan bidang kerja mulai dari titik ke-1 sampai dengan titik ke-15 mendapatkan penyinaran dengan warna kontur yang berbeda.

Dewa Ayu Sri Santiari : Kajian Area Penyinaran Dan Nilai Intensitas....

p-ISSN:1693 - 2951; e-ISSN: 2503-2372 
Kontur warna ungu dengan nilai intensitas $12-16 \mu \mathrm{W} / \mathrm{cm}^{2} / \mathrm{nm}$ adalah kontur dengan area yang paling luas, meliputi area pada titik ke-2, ke-4, ke-5, ke-6, ke-7, ke-8, ke-9, ke-10, ke-11, dan ke-12. Selanjutnya nilai intensitas $8-12 \mu \mathrm{W} / \mathrm{cm}^{2} / \mathrm{nm}$ diwakili oleh kontur warna hijau dengan area permukaan berada pada titik ke-1, ke-3, ke-13, ke-14, ke-15.

Grafik kontur yang dihasilkan menunjukkan bahwa pada saat blue light therapy dipasang $30 \mathrm{~cm}$ maka area penyinarannya adalah pada seluruh area (15 titik pengukuran) permukaan bidang kerja dengan semua nilai intensitasnya memenuhi intensitas penyinaran untuk fototerapi standar (8$\left.10 \mu \mathrm{W} / \mathrm{cm}^{2} / \mathrm{nm}\right)$.

Dengan menggunakan cara yang sama maka hasil pengukuran untuk jarak $35,40,45$, dan $50 \mathrm{~cm}$ dapat dilihat pada tabel II .

Tabel II

REKAP PENGUKURAN BLT LAMPU FLOURESCENT

\begin{tabular}{|c|c|c|c|c|}
\hline $\begin{array}{c}\text { No } \\
\cdot\end{array}$ & $\begin{array}{c}\text { Jarak } \\
(\mathrm{cm})\end{array}$ & $\begin{array}{c}\text { Intensitas } \\
\text { tertinggi } \\
\left(\mu \mathrm{W} / \mathrm{cm}^{2} / \mathrm{nm}\right)\end{array}$ & Titik & $\begin{array}{c}\text { Rata-rata } \\
\text { Intensitas } \\
\left(\mu \mathrm{W} / \mathrm{cm}^{2} / \mathrm{nm}\right)\end{array}$ \\
\hline 1 & 30 & 16 & 8,9 & 12 \\
\hline 2 & 35 & 12 & $5,8,9$ & 10 \\
\hline 3 & 40 & 10 & 8,9 & 8 \\
\hline 4 & 45 & 9 & 8,9 & 7 \\
\hline 5 & 50 & 7 & 8,9 & 6 \\
\hline
\end{tabular}

E. Pengukuran Intensitas Penyinaran Blue Light Therapy Lampu LED Pada Jarak $30 \mathrm{~s} / \mathrm{d} 50 \mathrm{~cm}$

Gambar 11 menunjukkan hasil penyinaran blue light therapy lampu $L E D$ pada jarak $30 \mathrm{~cm}$.

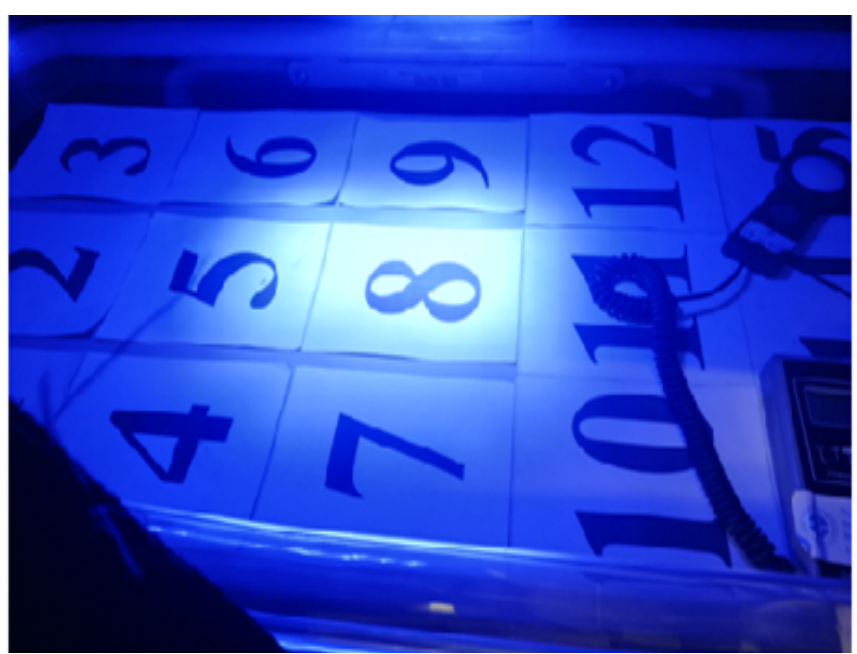

Gambar 11. Penyinaran BLT Lampu LED pada Jarak $30 \mathrm{~cm}$

Hasil konversi pengukuran intensitas penyinaran blue light therapy lampu LED pada jarak $30 \mathrm{~cm}$ dalam $\mu \mathrm{W} / \mathrm{cm}^{2} / \mathrm{nm}$ dapat dilihat pada tabel III. Sama seperti pada tabel I maka angka 1 sampai dengan 15 pada pojok kiri atas menunjukkan titik-titik pengukuran pada bidang kerja. Sedangkan nilai pada pojok kanan bawah adalah nilai konversi pengukuran intensitas penyinaran $B L T$.
Tabel III.

HASIL KONVERSI PENGUKURAN INTENSITAS PENYINARAN BLT LED JARAK 30 CM

\begin{tabular}{|c|c|c|}
\hline 0 & $\begin{array}{l}2 \\
0\end{array}$ & $\begin{array}{l}3 \\
0\end{array}$ \\
\hline $\mathbf{0}$ & 5 & 6 \\
\hline 1 & 27 & 9 \\
\hline 10 & 11 & 12 \\
\hline 13 & 14 & 15 \\
\hline
\end{tabular}

Dengan mengacu pada (2) maka diperoleh nilai rata-rata intensitas penyinaran sebesar $6 \mu \mathrm{W} / \mathrm{cm}^{2} / \mathrm{nm}$. Berdasarkan tabel III maka dihasilkan grafik kontur intensitas penyinaran seperti ditunjukkan pada gambar 11.

Tabel III menunjukkan hasil konversi pengukuran intensitas penyinaran blue light therapy lampu $L E D$ pada jarak $30 \mathrm{~cm}$. Pada tabel tersebut terlihat sembilan titik pengukuran memiliki nilai intensitas nol (0), hanya enam titik pengukuran saja, yaitu titik ke-5, ke-6, ke-7, ke-8, ke-9, dan ke-11 yang memiliki nilai intensitasnya dengan nilai tertinggi berada pada titik ke-8 sebesar $27 \mu \mathrm{W} / \mathrm{cm}^{2} / \mathrm{nm}$.

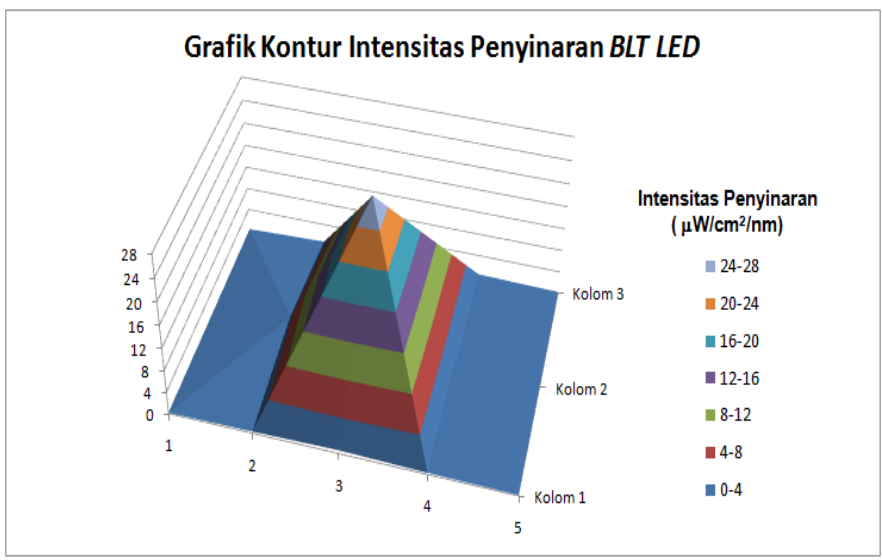

Gambar 12. Grafik Kontur Intensitas Penyinaran BLT LED pada Jarak $30 \mathrm{~cm}$

Dari enam titik pengukuran yang memiliki nilai intensitas, hanya titik ke-8 saja yang intensitasnya memenuhi nilai standar untuk fototerapi standar $\left(8-10 \mu \mathrm{W} / \mathrm{cm}^{2} / \mathrm{nm}\right)$. Adapun nilai rata-rata intensitas penyinaran pada saat blue light therapy lampu $L E D$ terpasang $30 \mathrm{~cm}$ dari bidang kerja adalah sebesar $6 \mu \mathrm{W} / \mathrm{cm}^{2} / \mathrm{nm}$.

Data pada tabel III menghasilkan grafik kontur intensitas penyinaran blue light therapy lampu LED (gambar 11). Pada grafik tersebut terlihat bahwa hanya pada titik pengukuran ke8 saja akan dihasilkan kontur-kontur yang nilai intensitasnya 
memenuhi. Kontur warna ungu muda, warna oranye, warna biru muda, warna ungu, dan warna hijau adalah kontur-kontur yang nilai intensitasnya memenuhi, dengan warna ungu muda sebagai kontur dengan nilai tertinggi.

Grafik kontur yang dihasilkan menunjukkan bahwa pada saat blue light therapy LED dipasang $30 \mathrm{~cm}$ dari bidang kerja maka area penyinarannya terbatas (sempit) hanya fokus pada 6 titik pengukuran yang berada tepat di bawah sumber cahaya.

Dengan menggunakan cara yang sama maka hasil pengukuran untuk jarak $35,40,45$, dan $50 \mathrm{~cm}$ dapat dilihat pada tabel IV berikut.

Tabel IV

REKAP PENGUKURAN BLT LAMPU LED

\begin{tabular}{|c|c|c|c|c|}
\hline $\begin{array}{c}\text { No } \\
\cdot\end{array}$ & $\begin{array}{c}\text { Jarak } \\
(\mathrm{cm})\end{array}$ & $\begin{array}{c}\text { Intensitas } \\
\text { tertinggi } \\
\left(\mu \mathrm{W} / \mathrm{cm}^{2} / \mathrm{nm}\right)\end{array}$ & Titik & $\begin{array}{c}\text { Rata-rata } \\
\text { Intensitas } \\
\left(\mu \mathrm{W} / \mathrm{cm}^{2} / \mathrm{nm}\right)\end{array}$ \\
\hline 1 & 30 & 27 & 8 & 6 \\
\hline 2 & 35 & 21 & 8 & 5 \\
\hline 3 & 40 & 18 & 8 & 4 \\
\hline 4 & 45 & 15 & 8 & 5 \\
\hline 5 & 50 & 13 & 8 & 4 \\
\hline
\end{tabular}

F. Analisa Bentuk Blue Light Therapy terhadap Area Penyinaran Bidang Kerja

Luas area penyinaran permukaan bidang kerja pada penelitian ini diasumsikan menggambarkan luasnya tubuh bayi yang terpapar sinar blue light. Semakin luas area penyinaran yang terpapar sinar blue light dengan intensitas yang memenuhi standar maka semakin luas pula tubuh bayi yang terpapar sinar blue light therapy.

Grafik kontur blue light therapy lampu fluorescent yang berbentuk persegi panjang dengan ukuran 65 x $35 \mathrm{~cm}$, menunjukkan hasil area penyinaran yang luas. Hal ini karena pancaran sinar peralatan tersebut mampu menyinari seluruh titik pengukuran pada permukaan tempat tidur bayi (bidang kerja). Sedangkan grafik kontur blue light therapy LED yang berbentuk persegi empat ukuran $10 \mathrm{~cm}$ x $10 \mathrm{~cm}$ akan menghasilkan area penyinaran terbatas (sempit). Dikatakan demikian karena pancaran sinar peralatan tersebut hanya terfokus pada wilayah titik pengukuran yang berada tepat di bawah sumber cahaya (lampu). Hasil ini menunjukkan bahwa bentuk alat terapi berpengaruh terhadap luas area penyinaran pada permukaan (bidang kerja).

G. Analisa Jarak Pemasangan terhadap Intensitas Area Penyinaran Blue Light Therapy Lampu Fluorescent

Hasil pengukuran dan grafik kontur intensitas penyinaran yang dihasilkan pada ke-5 jarak pemasangan blue light therapy lampu fluorescent menunjukkan bahwa semakin dekat jarak pemasangan alat terapi maka semakin besar pula nilai intensitas yang memenuhi pada area penyinarannya. Begitu pula sebaliknya semakin jauh jarak pemasangan alat terapi maka semakin kecil pula nilai intensitas yang memenuhi pada area penyinarannya. Selain itu nilai rata-rata intensitas penyinarannya juga semakin menurun apabila alat terapi dipasang semakin jauh dari bidang kerja. Hasil ini menyatakan jarak pemasangan lampu mempengaruhi intensitas pada area penyinarannya.

H. Analisa Jarak Pemasangan terhadap Intensitas Area Penyinaran Blue Light Therapy Lampu LED

Hasil pengukuran dan grafik kontur intensitas penyinaran yang dihasilkan pada ke-5 jarak pemasangan blue light therapy lampu LED juga menunjukkan bahwa semakin dekat jarak pemasangan alat terapi maka semakin besar pula nilai intensitas yang memenuhi pada area penyinarannya. Begitu pula sebaliknya semakin jauh jarak pemasangan alat terapi maka semakin kecil pula nilai intensitas yang memenuhi pada area penyinarannya. Hasil ini menyatakan bahwa jarak pemasangan lampu mempengaruhi intensitas pada area penyinarannya.

I. Analisa Efektifitas antara Blue Light Therapy Lampu Flourescent dengan Blue Light Therapy Lampu LED berdasarkan Luas Area dan Intensitas Penyinaran

Luasnya area tubuh neonatus (bayi) yang terpapar sinar dan tingginya nilai intensitas penyinaran adalah dua hal yang berpengaruh terhadap efektifitas tindakan fototerapi. Semakin luas area penyinaran permukaan yang terpapar sinar dengan intensitas yang tinggi maka semakin cepat pula proses penurunan kadar bilirubin pada bayi.

Blue light therapy lampu fluorescent adalah peralatan terapi yang mampu menghasilkan pancaran sinar yang menyinari seluruh titik pengukuran pada permukaan bidang kerja (tempat tidur bayi), dengan nilai intensitas rata-rata tertinggi sebesar $12 \mu \mathrm{W} / \mathrm{cm}^{2} / \mathrm{nm}$ pada jarak $30 \mathrm{~cm}$. Hasil ini menunjukkan bahwa blue light therapy lampu fluorescent dapat diasumsikan lebih luas menyinari permukaan tubuh neonatus (bayi) dengan intensitas sinar yang tinggi

Blue light therapy lampu $L E D$ adalah peralatan terapi yang pancaran sinarnya tidak mampu menyinari seluruh titik pengukuran pada permukaan bidang kerja (tempat tidur bayi). Dikatakan demikian karena pancaran sinar peralatan tersebut hanya terfokus (terbatas) pada wilayah sekitar titik pengukuran ke-8 yang berada tepat di bawah sumber cahaya (lampu). Adapun nilai intensitas rata-rata tertingginya adalah $6 \mu \mathrm{W} / \mathrm{cm}^{2} / \mathrm{nm}$ pada jarak $30 \mathrm{~cm}$. Nilai rata-rata ini tidak memenuhi untuk fototerapi standar $\left(8-10 \mu \mathrm{W} / \mathrm{cm}^{2} / \mathrm{nm}\right)$.

Apabila luas area dan intensitas penyinaran yang dihasilkan oleh kedua blue light therapy ini kita bandingkan pada jarak yang sama, yaitu $30 \mathrm{~cm}$ maka dapat diasumsikan bahwa blue light therapy lampu fluorescent akan lebih luas menyinari permukaan tubuh neonatus (bayi) dengan intensitas sinar yang tinggi. Sehingga hal ini akan berdampak terhadap kecepatan penurunan kadar bilirubin pada tubuh bayi.

Hasil tersebut menunjukkan bahwa blue light therapy lampu fluorescent lebih efektif dipergunakan sebagai alat fototerapi dibandingkan dengan blue light therapy LED.

\section{SIMPULAN}

Bentuk alat terapi berpengaruh terhadap luas area penyinaran pada permukaan (bidang kerja). Hal ini berdasarkan pada blue light therapy lampu fluorescent yang berbentuk persegi panjang menghasilkan area penyinaran 
yang lebih luas dari blue light therapy LED berbentuk persegi empat yang hanya menghasilkan area penyinaran terbatas pada permukaan bidang kerja.

Jarak pemasangan lampu mempengaruhi nilai intensitas pada area penyinarannya. Ini sesuai dengan hasil pengukuran dan grafik kontur intensitas penyinaran pada ke-5 jarak pemasangan blue light therapy baik lampu flourescent maupun lampu LED. Hasilnya menunjukkan bahwa semakin jauh jarak pemasangan alat terapi maka semakin kecil pula nilai intensitas yang memenuhi pada area penyinarannya. Blue light therapy lampu fluorescent yang berbentuk persegi panjang pada jarak pemasangan $30 \mathrm{~cm}$ akan menghasilkan area penyinaran yang lebih luas dengan intensitas rata-rata yang lebih tinggi $\left(12 \mu \mathrm{W} / \mathrm{cm}^{2} / \mathrm{nm}\right)$ dibandingkan dengan blue light therapy $L E D$ yang hanya menghasilkan area penyinaran terbatas dengan intensitas rata-rata yang lebih rendah $\left(6 \mu \mathrm{W} / \mathrm{cm}^{2} / \mathrm{nm}\right)$ pada jarak yang sama.

Dengan area penyinaran yang lebih luas dan nilai intensitas yang lebih tinggi menunjukkan bahwa blue light therapy lampu flourescent lebih efektif sebagai alat fototerapi dibandingkan dengan blue light therapy lampu LED.

\section{REFERENSI}

[1] IDAI, 2011. Pedoman Pelayanan Medis Ikatan Dokter Anak Indonesia Edisi II. Jakarta. Badan Penerbit Ikatan Dokter Anak Indonesia.

[2] Saifuddin, A. B. 2007. Buku Acuan Nasional Pelayanan Kesehatan Maternal dan Neonatal. Jakarta. Yayasan Bina Pustaka Sarwono Prawiroharjo.

[3] Khosim, MS. 2004. Buku Panduan Manajemen Masalah Bayi Baru Lahir untuk Dokter, Bidan, dan Perawat di Rumah Sakit. Jakarta. IDAI.

[4] Gomella, T. L. 2009. Hyperbilirubinemia Indirect (Unconjugated Hyperbilirubinemia) : Management, Procedures, on-call, Disease and Drug. Seventh edition. Lange Medical Books.

[5] Maulida, L. F. 2013. Ikterus Neonatorum. PROFESI. Volume 10 / September 2013 -Februari 2014.

[6] Sunardi, dkk. 2012.Fisika Berbasis Pendidikan Karakter Bangsa. Bandung. PT Srikandi Empat Widya Utama.

[7] Stokowski, L. A. 2006. Fundamentals of Phototherapy for Neonatal Jaundice. Advancesin Neonatal Care, 11 (5S): S10-S21.

[8] Hobbie R., Roth B. 2015. Intermediate Physics for Medicine and Biology. Fifth Edition. USA. Springer. Diunduh dari URL : http://www.springerlink.com pada tanggal 30 Mei 2018.

[9] Maisels, M.J., Donagh, F.A. 2008. Phototherapy for Neonatal Jaundice. N Engl J M. 358:920-8.

[10] American Academy of Pediatrics (AAP), Subcommitte on Hyperbilirubinemia. 2004. Management of Hyperbilirubinemia in the Newborn Infant 35 or More Weeks of Gestation. Pediatrics. 114 : 297316.

[11] Buthani, VK. MD. and The Committee on Fetus and Newborn. 2011 Phototherapy to Prevent Severe Neonatal Hyperbilirubinemia in the Newborn Infant 35 or More Weeks of Gestation. Pediatrics. 128 :10461052 .

[12] Brandao D., Draque C., Sanudo A., Filho G., Almeida M. LED versus Daylight Phototherapy at Low Irradiance in Newborns $=35$ Weeks of Gestation : Randomized Controlled Trial. J Matern Fetal Neonatal Med $2015 ; 28: 172530$.

[13] Kepmenkes RI, 2014. Keputusan Menteri Kesehatan Republik Indonesia No. 118/ Menkes/ SK/ IV/ 2014 Tentang Kompendium Alat Kesehatan. Menteri Kesehatan RI. Jakarta.

[14] Swamardika, I.B. A. 2009. Pengaruh Radiasi Gelombang Elektromagnetik terhadap Kesehatan Manusia. Majalah Ilmiah Teknologi Elektro. Volume 8 No. 1 Januari - Juni 2009.

[15] Harten, P., Van. 1985. Instalasi Listrik Arus Kuat 2. Bandung. Binacipta.

[16] Muhaimin. 2001. Teknologi Pencahayaan. Bandung. PT. Refika Aditama.

[17] Chumaidy, A. 2017. Analisa Perbandingan Penggunaan Lampu TL, CFL, dan Lampu LED. Sinusoida Vol. XIX No.1.
[18] JB Medical Supplies. 2018. Bilitron 3006 Product Catalog. Diunduh dari http://www.jbmedicalsupplies.com.au/our-products/bilitron-3, pada tanggal 18 Januari 2018.

[19] David, Ningbo. 2018. XHZ-90 Neonate bilirubin Phototheraphy Equipment. Ningbo David Medical Device CO.LTD. China.

[20] Jaya Multi Mandiri. 2018. Katalog Produk Lux Meter. Diunduh dari https://digital-meter-indonesia.com/lux-meter-alat-pengukur-cahaya, pada tanggal 20 Januari 2018

[21] Rory. 2016. Rumus Statistik. Diunduh dari https://www.rumusstatistik.com/2013/07/rata-rata-mean-atau-rataan.html, pada tanggal 27Maret 2018. 